\title{
Power Characteristics Analysis of Maximum Power Point Tracking (MPPT) and Pulse Width Modulation (PWM)
}

\section{Analisa Karakteristik Daya Pengunaan Maximum Power Point Tracking (MPPT) dan Pulse Widht Modulation (PWM)}

\author{
Ilham Ramadhana Chofananda ${ }^{1}$, Jamaaluddin Jamaaluddin ${ }^{2}$, Arief Wisaksono ${ }^{3}$, Izza Anshory ${ }^{4}$ \\ \{ilhamramadhana1989@gmail.com¹, jamaaluddin@umsida.ac.id² ariefwisaksono@umsida.ac.id ${ }^{3}$ izzaanshory@umsida.ac.id ${ }^{4}$ \}
}

Program Studi Teknik Elektro Fakultas Sains dan Teknologi Universitas Muhammadiyah Sidoarjo

\begin{abstract}
Solar energy is a source of energy and has advantages compared to fossil energy. Indeed, further research and development of this type of solar power is needed, including at the University of Muhammadiyah Sidoarjo. The use of solar energy is carried out by installing photovoltaic $(P V)$ cells with a photovoltaic output control system that uses MPPT (Maximum Power Point Tracking) and PWM (Pulse Width Modulation) to regulate the load used and charge the battery. The two PV control methods have different characteristics. These differences will be analyzed based on the characteristics of the load and sunlight contained in the electrical engineering laboratory of the Muhammadiyah University of Sidoarjo. It can be seen from the results of the analysis that at power above $200 \mathrm{~W}$, MPPT has a better voltage stability than PWM.
\end{abstract}

Keywords - PWM; MPPT; Solar energy

\begin{abstract}
Abstrak. Energi matahari merupakan salah satu sumber energi dan memiliki kelebihan dibandingkan dengan energi fosil, Memang perlu adanya penelitian dan pengembangan lebih lanjut jenis tenaga surya ini, termasuk di Universitas Muhammadiyah Sidoarjo. Penggunaan energi matahari dilakukan dengan memasang sel fotovoltaik $(P V)$ dengan sistem kendali keluaran fotovoltaik yang menggunakan MPPT (Maximum Power Point Tracking) dan PWM (Pulse Width Modulation) untuk mengatur beban yang digunakan dan mengisi baterai. Kedua metode pengendalian PV tersebut memiliki karakteristik yang berbeda. Perbedaan tersebut akan dianalisis berdasarkan karakteristik beban dan sinar matahari yang terdapat di laboratorium teknik elektro Universitas Muhammadiyah Sidoarjo. Dapat dilihat dari hasil analisis bahwa pada daya diatas 200 W, MPPT memiliki kestabilan tegangan yang lebih baik dari PWM.
\end{abstract}

Kata Kunci - PWM; MPPT; Energi Surya

\section{Pendahuluan}

Di jaman ini energi listrik menjadi kebutuhan utama untuk manusia pertumbuhan penggunaan listrik di dunia semakin tinggi setiap tahunnya dan salah satu indikator negara yang maju di ukur dari penggunaan energy listriknya. Negara pada umumnya masih menggunakan energi fosil untuk diubah menjadi energi listrik, dan kebutuhan energi diperkirakan memiliki rata-rata sebesar 4,7 \% per tahun pada periode tahun 2011-2030. Dengan mengikuti berjalannya waktu[1][2][3].

Negara Indonesia berada di garis katulistiwa mempunyai sumber daya energi yang beraneka ragam, seperti energi angin, energi air, batu bara, biomassa, biogas, gelombang laut, gas bumi, matahari dan lain .Pada penelitian ini, akan dimanfaatkan PLTS itu untuk menjadi sumber energi alternatif pada Laboratorium Teknik Elektro Universitas Muhammadiyah Sidoarjo, Penelitian ini menganalisa efisiensi penggunaan pengatur daya masuk dari matahari dan pembagian bebannya yang kearah beban beban terpakai dan kearah penyimpanan energi atau accu.

Permasalahan lain disebabkan pada pemakaian PhotoVoltaic ialah arus dan tegangan keluaran PhotoVoltaic yang kerap kali kurang sesuai dengan standar arus dan tegangan sebenarnya yang dihasilkan oleh PhotoVoltaic pada saat keadaan langit sedang mendung[4][5].

Hal ini berdampak pada pengisian PV ke baterai, pengisian akan normal-normal saja ketika kondisi matahari normal ataupun terang, sehingga tegangan pada PV lebih besar dari pada baterai dan pengisian akan berlangsung normal, akan tetapi pada saat matahari sedang mendung ataupun berawan, penyerapan energi yang dilakukan PV akan tidak optimal yang mengakibatkan tegangan baterai akan lebih besar dari pada PV, yang justru akan membuat PV menjadi beban yang akan di suplay oleh baterai[6][7].

Maka dari itu dibutuhkan rangkaian konverter untuk meningkatkan efisiensi keluaran dari panel surya tersebut, karena tegangan dan arus yang dihasilkan oleh PV merupakan tegangan dan arus DC, maka diperlukan rangkaian konverter DC-DC untuk menaikkan tegangan keluaran dari PV Pada penggunaan sistem pengaturan ini dikenal ada 2 sistem yaitu menggunakan MPPT (Maximum Power Point Tracking) Dan PWM (Pulse Width Modulation). Masing - masing sistem pengaturan tersebut memiliki karakteristik dan kemampuan masing - masing. Oleh 
karenanya pada penelitian ini akan dilakukan analisa percobaan dan pelaksanaan prakteknya sehingga di dapatkan sistem pengaturan yang paling baik untuk SBS yang akan di aplikasikan pada Ruangan Laboratorium Teknik Tenaga Listrik Program Studi Teknik Elektro Universitas Muhammadiyah Sidoarjo sehingga dapat mengurangi pembiayaan tagihan energi listrik yang disuplai oleh PT PLN[8][9].

\section{METODE}

Pada penelitian ini data yang diambil adalah pengujian untuk mengetahui kinerja PLTS apakah berfungsi dengan baik. melakukan pengujian dan pengukuran pada titik pada komponen PV, MPPT, Baterai, dan juga load Adapun Penelitian ini dilaksanakan beberapa Tahapan sebagai berikut:

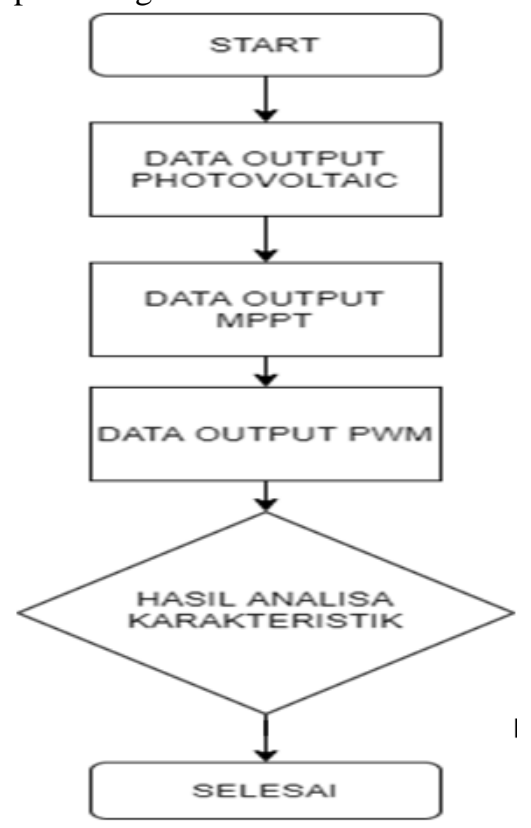

Gambar 1. Flowchart sistem

1. Tahap Pertama yaitu Pemasangan Sistem PLTS di Laboratorim Teknik Elektro Kampus 2 Universitas Muhammadiyah Sidarjo

2. Tahap Kedua yaitu Pengumpulan data output tegangan, arus, serta daya pada tiap panel distribusi jenis MPPT dan PWM

3. Tahap ketiga yaitu menganalisa karakteristik rata rata daya tiap jam dan dibuatkan grafik agar mempermudah melihat hasil pengukuran selama 3 jam

\section{HaSil Dan PembahaSan}

\section{A. Pemasangan sistem plts di laboratorium teknik elektro}

Pemasangan sistem PLTS di Laboratrorium Teknik Elektro disini menggunakan dua panel box yang berisi masing masing jenis Solar Charge Controller yang ditunjukan pada gambar 2 dan gambar 3

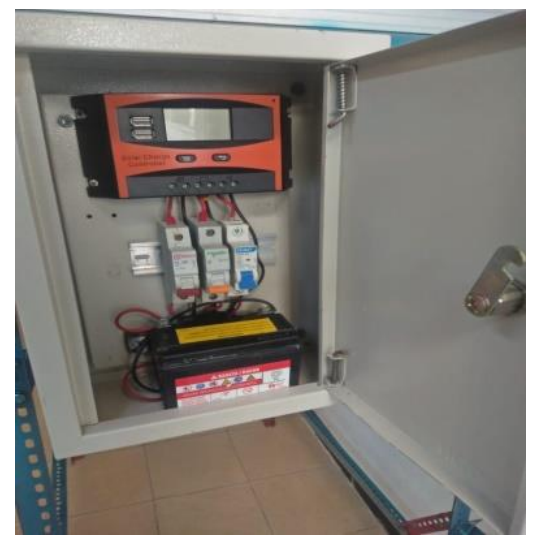

Gambar 2. Panel box PWM 


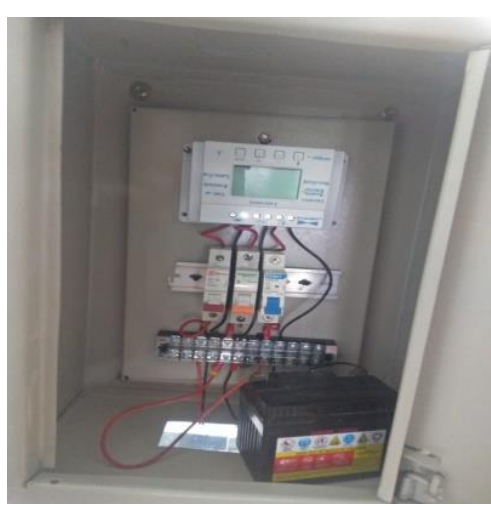

Gambar 3. Panel Box MPPT

\section{B. Pengukuran yang dilakukan}

Pengukuran Yang digunakan pada pelaksanaan penelitian ini ada beberapa prosedur, yaitu:

1) Pengukuran arus maupun tegangan output dari PV menggunakan AVOmeter digital tiap 30 menit selama 1 jam pada puncak siang hari. Dilaksanakan selama 3 hari.

2) Pengukuran arus maupun tegangan ke arah baterai menggunakan AVOmeter digital tiap 30 menit selama 1 jam pada puncak siang hari. Dilaksanakan selama 3 hari.

3) Pengukuran arus maupun tegangan ke arah beban menggunakan AVOmeter digital tiap 30 menit selama 1 jam pada puncak siang hari. Dilaksanakan selama 3 hari.

Dengan ketentuan selayaknya dibawah ini:

1) Beban yang digunakan berada dibawah 100WP

2) Semua prosedur pengukuran yang ada di atas di berlakukan pada panel box PWM maupun MPPT.

\section{Hasil pengukuran}

Pengujian ini dilaksanakan beberapa kali dengan menggunakan PV 100WP sebanyak 1 buaj, Controller PWM 20A 11 unit dan MPPT 20 A 1 unit. hasil pengukuran ditampilkan pada tabel 1 hingga tabel 6 dibawah ini:

Tabel 1. PWM pada tanggal 25 Maret 2021

\begin{tabular}{cccccccccc}
\hline PWM & & PV & \multicolumn{3}{c}{ Baterry } & \multicolumn{3}{c}{ Load } \\
TIME & V & A & W & V & A & W & V & A & W \\
\hline 11.30 & 12.50 & 1.7 & 21.25 & 12.50 & 1.7 & 21.25 & 9.70 & 1.7 & 16.49 \\
\hline 12.00 & 12.50 & 1.6 & 20 & 12.50 & 1.75 & 21.87 & 9.30 & 1.7 & 15.81 \\
\hline 12.30 & 12.00 & 1.6 & 19.2 & 11.30 & 1.7 & 19.21 & 12.10 & 1.65 & 19.96
\end{tabular}

Tabel 2. MPPT pada tanggal 25 Maret 2021

\begin{tabular}{cccccccccc}
\hline MPPT & & PV & \multicolumn{3}{c}{ Baterry } & \multicolumn{3}{c}{ Load } \\
TIME & V & A & W & V & A & W & V & A & W \\
\hline 11.30 & 14.30 & 1.60 & 22.88 & 12.10 & 1.60 & 19.36 & 12.10 & 1.5 & 18.15 \\
\hline 12.00 & 14.30 & 1.60 & 22.88 & 12.00 & 1.60 & 19.2 & 12.10 & 1.5 & 18.15 \\
\hline 12.30 & 14.30 & 1.60 & 22.88 & 12.00 & 1.60 & 19.2 & 12.10 & 1.5 & 18.15 \\
\hline
\end{tabular}

Tabel 3. PWM pada tanggal 26 Maret 2021

\begin{tabular}{cccccccccc}
\hline PWM & & PV & \multicolumn{3}{c}{ Baterry } & \multicolumn{3}{c}{ Load } \\
TIME & V & A & W & V & A & W & V & A & W \\
\hline 11.30 & 12.50 & 1.7 & 21.25 & 12.50 & 1.7 & 21.25 & 12.10 & 1.5 & 20.57 \\
\hline 12.00 & 12.50 & 1.6 & 20 & 12.50 & 1.75 & 21.87 & 12.10 & 1.5 & 20.57 \\
\hline 12.30 & 12.00 & 1.6 & 19.2 & 11.30 & 1.7 & 19.21 & 12.10 & 1.5 & 19.96 \\
\hline
\end{tabular}


Tabel 4. MPPT pada tanggal 26 Maret 2021

\begin{tabular}{cccccccccc}
\hline $\begin{array}{c}\text { MPPT } \\
\text { TIME }\end{array}$ & V & PV & W & V & A & W & V & A & W \\
\hline 11.30 & 14.30 & 1.60 & 22.88 & 12.10 & 1.60 & 19.36 & 12.10 & 1.5 & 18.15 \\
\hline 12.00 & 14.30 & 1.60 & 22.88 & 12.00 & 1.60 & 19.2 & 12.10 & 1.5 & 18.15 \\
\hline 12.30 & 14.30 & 1.60 & 22.88 & 12.00 & 1.60 & 19.2 & 12.10 & 1.5 & 18.15 \\
\hline
\end{tabular}

Tabel 5. PWM pada tanggal 27 Maret 2021

\begin{tabular}{cccccccccc}
\hline PWM & \multicolumn{3}{c}{ PV } & \multicolumn{3}{c}{ Baterry } & \multicolumn{3}{c}{ Load } \\
TIME & $\mathrm{V}$ & $\mathrm{A}$ & $\mathrm{W}$ & $\mathrm{V}$ & $\mathrm{A}$ & $\mathrm{W}$ & $\mathrm{V}$ & $\mathrm{A}$ & $\mathrm{W}$ \\
\hline 11.30 & 12.45 & 1.7 & 21.16 & 12.30 & 1.7 & 20.91 & 9.70 & 1.7 & 16.49 \\
\hline 12.00 & 12.45 & 1.6 & 19.92 & 12.30 & 1.75 & 21.52 & 9.30 & 1.7 & 15.81 \\
\hline 12.30 & 12.45 & 1.6 & 19.92 & 12.30 & 1.7 & 20.91 & 12.10 & 1.65 & 19.96 \\
\hline
\end{tabular}

Tabel 6. MPPT pada tanggal 27 Maret 2021

\begin{tabular}{cccccccccc}
\hline $\begin{array}{c}\text { MPPT } \\
\text { TIME }\end{array}$ & V & PV & W & V & A & W & V & A & W \\
\hline 11.30 & 14.18 & 1.60 & 22.68 & 12.10 & 1.60 & 19.36 & 12.20 & 1.5 & 18.3 \\
\hline 12.00 & 14.18 & 1.60 & 22.68 & 12.00 & 1.60 & 19.2 & 12.20 & 1.5 & 18.3 \\
\hline 12.30 & 14.18 & 1.60 & 22.68 & 12.00 & 1.60 & 19.2 & 12.20 & 1.5 & 18.3 \\
\hline
\end{tabular}

Dari data tabel 1 hingga tabel 6 yang didapatkan diatas, dibuatlah rata-rata daya perpengukuran selama 3 hari pada titik distribusi panel box PWM maupun MPPT pada tabel 7 hingga tabel 12 dibawah ini:

Tabel 7. Rata rata Daya PV menggunakan PWM

\begin{tabular}{|c|c|c|c|c|c|}
\hline PWM & & HARI & & & \\
\hline TIME & 1 & 2 & 3 & JUMLAH & RATA-RATA \\
\hline 11.30 & 21.25 & 21.25 & 21.16 & 63.66 & 21.22 \\
\hline 12.00 & 20 & 20 & 19.92 & 59.92 & 19.97 \\
\hline 12.30 & 19.2 & 19.2 & 19.92 & 58.32 & 19.44 \\
\hline
\end{tabular}

Tabel 8. Rata rata Daya PV menggunakan MPPT

\begin{tabular}{cccccc}
\hline $\begin{array}{c}\text { MPPT } \\
\text { TIME }\end{array}$ & 1 & 2 & 3 & JUMLAH & RATA-RATA \\
\hline 11.30 & 22.88 & 22.88 & 22.68 & 68.44 & 22.81 \\
\hline 12.00 & 22.88 & 22.88 & 22.68 & 68.44 & 22.81 \\
\hline 12.30 & 22.88 & 22.88 & 22.68 & 68.44 & 22.81 \\
\hline
\end{tabular}

Tabel 9. Rata rata Daya Baterai menggunakan PWM

\begin{tabular}{cccccc}
\hline PWM & \multicolumn{5}{c}{ HARI } \\
TIME & 1 & 2 & 3 & JUMLAH & RATA-RATA \\
\hline 11.30 & 21.25 & 19.36 & 16.49 & 57.1 & 19.03 \\
\hline
\end{tabular}


Procedia of Engineering and Life Science Vol. 1. No. 2 Juni 2021

Seminar Nasional \& Call Paper Fakultas Sains dan Teknologi (SENASAINS 2nd)

Universitas Muhammadiyah Sidoarjo

\begin{tabular}{llllll}
\hline 12.00 & 21.87 & 19.2 & 15.81 & 56.88 & 18.96 \\
\hline 12.30 & 19.21 & 19.2 & 19.96 & 58.37 & 19.45 \\
\hline
\end{tabular}

Tabel 10. Rata rata Daya Baterai menggunakan MPPT

\begin{tabular}{|c|c|c|c|c|c|}
\hline MPPT & & HARI & & & \\
\hline TIME & 1 & 2 & 3 & JUMLAH & RATA-RATA \\
\hline 11.30 & 19.36 & 19.36 & 19.36 & 58.08 & 19.36 \\
\hline 12.00 & 19.2 & 19.2 & 19.2 & 57.6 & 19.2 \\
\hline 12.30 & 19.2 & 19.2 & 19.2 & 57.6 & 19.2 \\
\hline
\end{tabular}

Tabel 11. Rata rata Daya Beban menggunakan PWM

\begin{tabular}{cccccc}
\hline PWM & \multicolumn{5}{c}{ HARI } \\
TIME & 1 & 2 & 3 & JUMLAH & RATA-RATA \\
\hline 11.30 & 16.49 & 20.57 & 16.49 & 53.55 & 17.85 \\
\hline 12.00 & 15.81 & 20.57 & 15.81 & 52.19 & 17.39 \\
\hline 12.30 & 19.96 & 19.96 & 19.96 & 59.88 & 19.96 \\
\hline
\end{tabular}

Tabel 12. Rata rata Daya Beban menggunakan MPPT

\begin{tabular}{cccccc}
\hline MPPT & \multicolumn{5}{c}{ HARI } \\
TIME & 1 & 2 & 3 & JUMLAH & RATA-RATA \\
\hline 11.30 & 18.15 & 18.15 & 18.3 & 54.6 & 18.2 \\
\hline 12.00 & 18.15 & 18.15 & 18.3 & 54.6 & 18.2 \\
\hline 12.30 & 18.15 & 18.15 & 18.3 & 54.6 & 18.2 \\
\hline
\end{tabular}

Hasil perhitungan rata rata pengukuran pada Tabel 7. hingga Tabel 12., maka diperjelas sebagaimana grafik pada Gambar 3. hingga Gambar 8. dibawah ini:

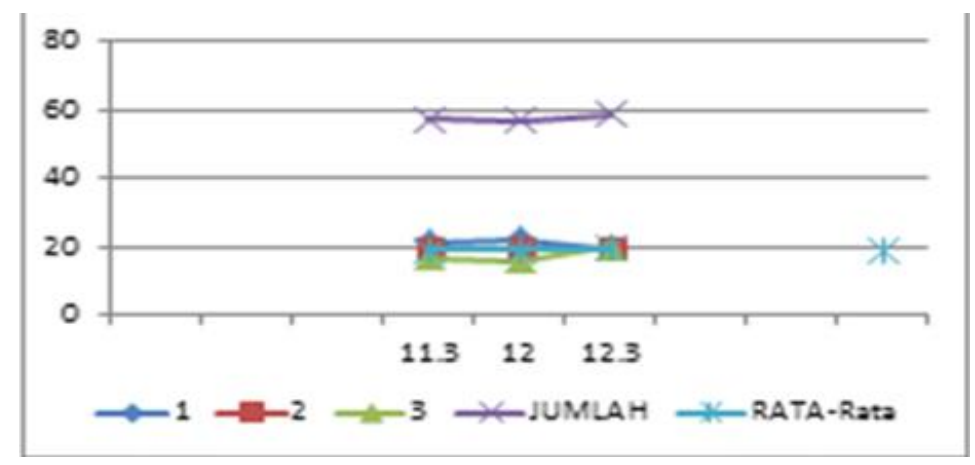

Gambar 3. Grafik perbandingan daya PV menggunakan PWM 
Procedia of Engineering and Life Science Vol. 1. No. 2 Juni 2021

Seminar Nasional \& Call Paper Fakultas Sains dan Teknologi (SENASAINS 2nd)

Universitas Muhammadiyah Sidoarjo

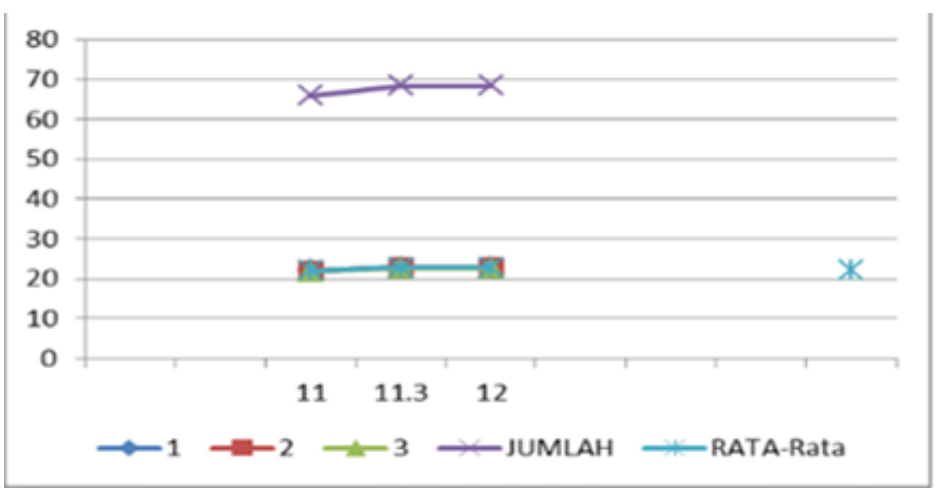

Gambar 4. Grafik perbandingan daya PV menggunakan MPPT

Penjelasan dari Gambar 3. dan Gambar 4. Bahwa penyerapan MPPT menampilkan daya serap yang lebih stabil di angka 22W dibandingkan penyerapan PWM yang naik turun di angka 19W-21W.

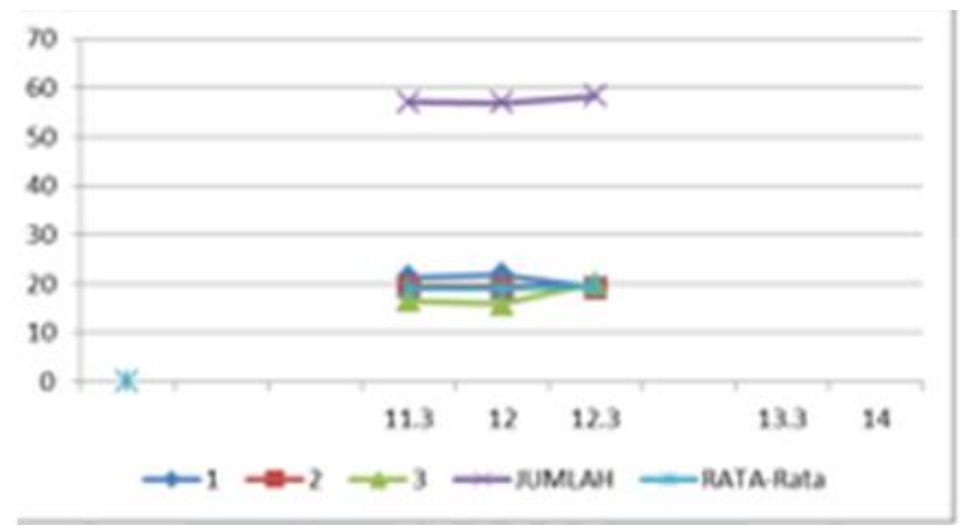

Gambar 5. Grafik perbandingan daya Baterai menggunakan PWM

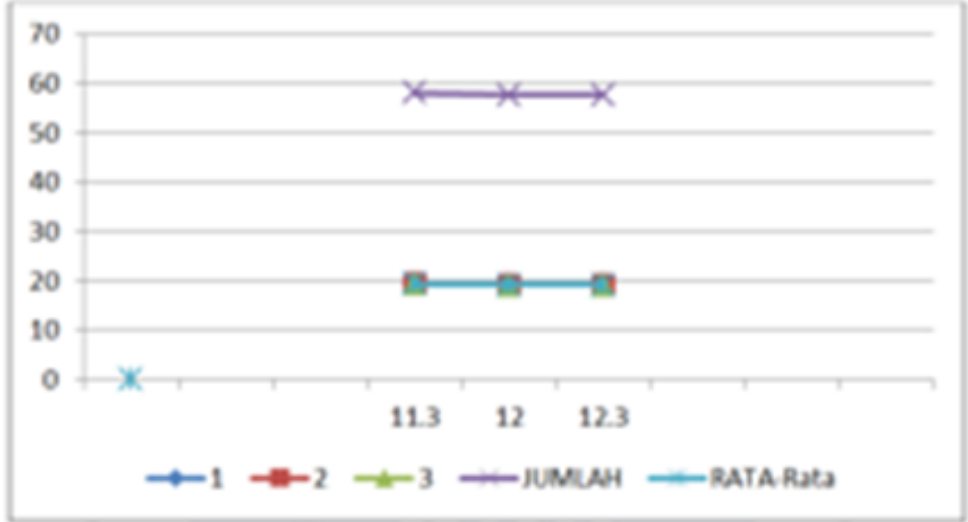

Gambar 6. Grafik perbandingan daya Baterai menggunakan MPPT

Penjelasan dari Gambar 5. Dan Gambar 6. Bahwa daya yang disuplay MPPT menampilkan yang lebih stabil pada angka $19.2 \mathrm{~W}$ dibandingkan pensupplyan daya PWM yang masih sedikit kurang stabil. 


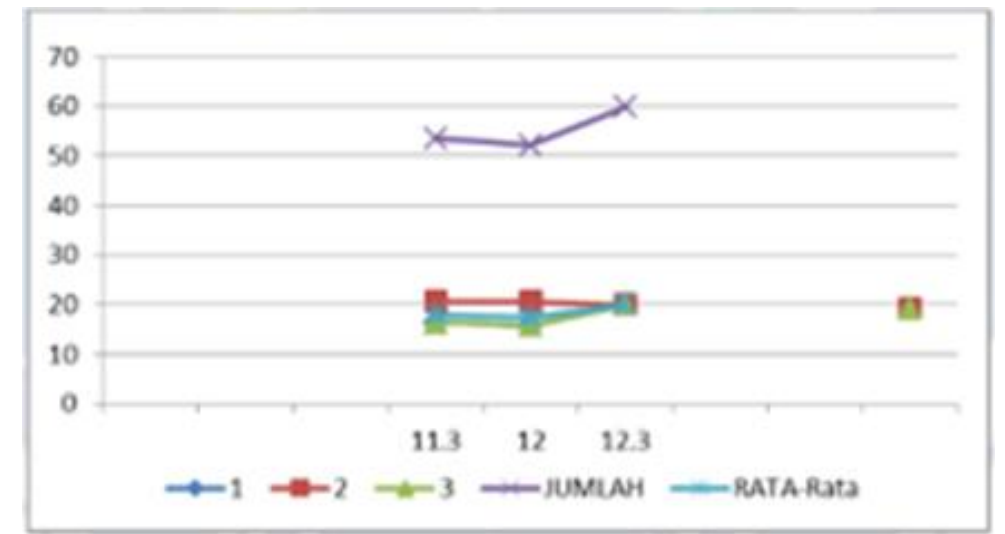

Gambar 7. Grafik perbandingan daya Beban Lampu menggunakan PWM (kiri) MPPT (kanan)

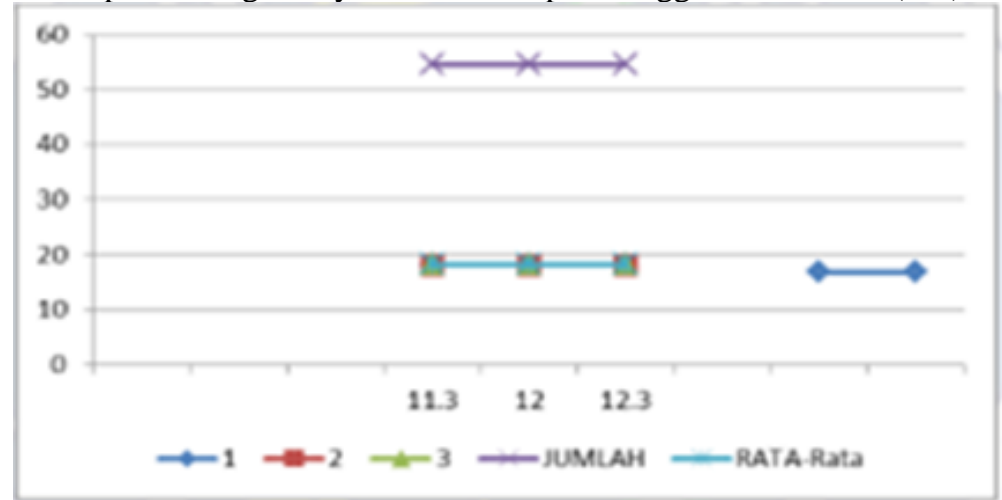

Gambar 8. Grafik perbandingan daya Beban Lampu menggunakan PWM (kiri) MPPT (kanan)

Penjelasan dari Gambar 7. dan Gambar 8. Bahwa daya yang distribusi MPPT menampilkan stabil pada angka 18W dibandingkan distribusi daya PWM yang masih naik dan turun di angka 17W-19W.

\section{KESIMPULAN}

Berdasarkan pengukuran pada system PLTS selama tiga hari, didapatkan data perhitungan dan analisis data karakteristik daya penggunaan Maximum Power Point Tracking (MPPT) untuk beberapa titik pengujian menunjukan hasil grafik yang stabil, direkomendasikan digunakan khusus beban diatas 100W agar lebih maksimal dan Pulse Midth Modulation (PWM) menunjukan hasil yang sedikit kurang stabil dengan hasil grafik ang naik turun, direkomendasikan untuk beban kurang dari 50W.

\section{REFERENSI}

[1] J. Jamaaluddin and V. Wakhidian, "Rancang Bangun Alat Tes Busi Motor Di Bengkel Motor," J. Elektron. List. Telekomun. Komputer, Inform. Sist. Kontro, vol. 1, no. 2, pp. 66-70, 2019, doi: 10.30649/j-eltrik.v1i2.14.

[2] F. Birol, L. Cozzi, T. Gould, A. Bromhead, and R. Priddle, "World Energy Outlook 2015 Executive summary," 2015.

[3] I. Anshory, "Transfer Function Modeling and Optimization Speed Response of Bldc Motor E-Bike Using Intelligent Controller,” vol. 16, no. 1, pp. 305-324, 2021.

[4] I. Anshory, D. Hadidjaja, and Jakaria, "BLDC MOTOR : MODELING AND OPTIMIZATION SPEED,” vol. 25, no. 2, pp. 51-58, 2020.

[5] A. Wisaksono, "Design and Development of Parking Motor Parking Information System Design and Development of Parking Motor Parking Information System at Muhammadiyah University, Sidoarjo,” 2020, doi: 10.1088/1757-899X/874/1/012015.

[6] A. Wisaksono, "Design of Monitoring and Control of Energy Use in Multi-storey Buildings based on IoT," vol. 4, no. 2, pp. 128-135, 2020. 
[7] B. H. Purwoto, "Efisiensi Penggunaan Panel Surya Sebagai Sumber Energi Alternatif," Emit. J. Tek. Elektro, vol. 18, no. 01, pp. 10-14, 2018, doi: 10.23917/emitor.v18i01.6251.

[8] J. Uddin and S. Sumarno, "Perencanaan Sistem Pentanahan Tenaga Listrik Terintegrasi Pada Bangunan," J. Electr. Electron. Eng., vol. 1, no. 1, p. 29, 2017, doi: 10.21070/jeeeu.v1i1.375.

[9] A. Supriyadi, J. Jamaaluddin, T. Elektro, and U. Muhammadiyah, "Analisa Efisiensi Penjejak Sinar Matahari Dengan Menggunakan,” Jeee-U, vol. 2, no. APRIL, 2018, pp. 815,2018 